\title{
Pelaksanaan Upacara Ritual Dalam Tantrayana
}

\section{Rita Istari}

Keywords: tradition, ritual, hindu, assimilation, culture

\section{How to Cite:}

Istari, R. (2002). Pelaksanaan Upacara Ritual Dalam Tantrayana. Berkala Arkeologi, 22(1), 40-48. https://doi.org/10.30883/jba.v22i1.848

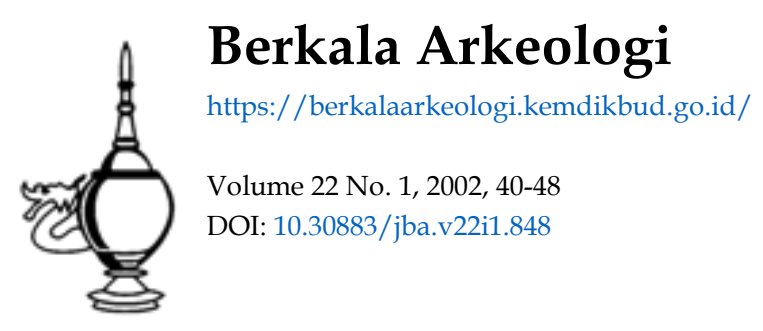

\section{(c) (1) (2)(2)}

This work is licensed under a Creative Commons Attribution-NonCommercial-ShareAlike 4.0 International License. 


\title{
PELAKSANAAN UPACARA RITUAL DALAM TANTRAYANA
}

\author{
T.M. Rita Istari \\ (Balai Arkeologi Yogyakarta)
}

\section{Pendahuluan}

Merupakan suatu kenyataan bahwa sejak Indonesia mengenal agama Hindhu dan Budha, telah terjadi adanya rasa toleransi di kalangan masyarakat terhadap kedua agama tersebut. Hubungan kedua agama itu sangat erat, terbukti dengan terwujudnya sinkretisme atau perpaduan antara keduanya. Sinkretisme Hindhu-Budha ini sangat menonjol peranannya pada masa Jawa Timur akhir, maka hampir semua bidang kebudayaan seperti seni bangun dan seni sastra bernafaskan keagamaan.(Mulyana, 1979). Dalam perkembangan selanjutnya, akibat adanya sinkretisme tersebut timbul suatu aliran baru yang disebut aliran Tantrayana. Menurut Pott, selain istilah Tantrayana disebut pula dengan istilah Vajrayana, Mantrayana dan Mantranaya (Pott, 1966). Arti masing-masing istilah tersebut adalah : Tantrayana secara harfiah berarti: aliran atau paham yang berkaitan dengan Tantra, Vajrayana adalah bentuk Tantra dalam agama Budha Mahayana, sedangkan Mantrayana dan Mantranaya menunjukkan suatu aliran/paham yang berhubungan dengan masalah mantra-mantra. (Kats, 1910).

Meskipun istilah itu ber macam-macam dan belum ada kebakuan dalam penggunaan istilah tersebut namun istilah yang lazim digunakan adalah Tantrayana.(Nurhadi, 1982). Dalam ajaran Tantrayana diutamakan pemujaan terhadap segala sesuatu yang bersifat gaib dan unsur wanita atau dewi. Sedangkan unsur wanita dalam agama Hindhu maupun Budha dikenal dengan sebutan Sakti, yang dilambangkan sebagai istri dewa dan dianggap merupakan sumber kekuatan dari dewa tersebut. Bermacammacam upacara dan kewajiban dilaksanakan untuk memuja Sakti tersebut menurut aliran masing-masing, misalnya dengan mengucapkan mantra-mantra, mengadakan saji-sajian, dan sebagainya. Dengan jalan itulah mereka beranggapan dapat bersatu dengan dewa yang dipujanya.(Kempers, 1954). Upacara pemujaan kepada Sakti ini menimbulkan kesan yang kurang baik karena dianggap melanggar kesopanan.Hal ini berkaitan dengan anggapan bahwa Tantrayana melaksanakan unsur-unsur yang dinilai sebagai ilmu sihir dan pemujaan kepada roh jahat.(Nurhadi, 1982).

Sebagaimana diketahui, Tantrayana pertama kali muncul di India dan dianut sampai sekarang oleh Bangsa Tibet.(Nurhadi, 1982). Sedang di Indonesia persebarannya berawal dari kerajaan Sriwijaya sekitar tahun 684 Masehi, terdapat dalam prasasti Talangtuwo yang menyebutkan kata :Vajrasarira (Poerbatjaraka, 1951). Sekitar abad 13, ditemukan pula peninggalan Tantra yang berasal dari masa pemerintahan 
Adityawarman, sebuah prasasti berangka tahun 1375 Masehi yang menguraikan tentang upacara menggunakan korban yang dilakukan oleh Adityawarman sebagai penganut Budha-Tantra. Di Jawa Tengah, pengarut Tantrayana ada sejak masa pemerintahan raja Panangkaran. Dalam prasasti Kalasan 778 Masehi disebutkan tentang pembangunan candi Kalasan yang bersifat Tantrayana bagi pemujaan kepada Dewi Tara (Sudiman, 1977). Sebelum pemerintahan raja Krtanagara sebenarnya aliran Tantra sudah berkembang, yaitu sewaktu pemerintahan raja Mpu Sindok. Agama yang dianut oleh Mpu Sindok adalah agama Hindhu, tetapi pada masa pemerintahannya sebuah kitab suci agama Budha yaitu Sang Hyang Kamahayanikan berhasil disusun. Kitab tersebut menguraikan soal-soal ajaran agama Budha aliran Tantrayana.(Hall, 1960). Di Bali, peninggalan yang mencerminkan adanya aliran Tantra yaitu berupa arca Siwa Bhairawa di Pura Kebo Edan, desa Pejeng, Kabupaten Gianyar. Arca ini menggambarkan raja Bali terakhir yaitu Paduka Bhatara Sri Astasura Ratna Bumi Banten yang memerintah antara tahun 1337-1343 Masehi.(Sukarto, 1983).

Berdasarkan penelitian, peninggalan Tantrayana di Indonesia ternyata hanya ditemukan di Sumatra, Jawa dan Bali saja. Beberapa upacara tradisional di Jawa maupun Bali yang masih ada sampai sekarang, mempunyai kesamaan dengan upacara Tantrayana pada masa dahulu. Maka kemungkinan upacara tradisional tersebut merupakan kelangsungan dari aliran Tantrayana yang pernah berkembang di Sumatra, Jawa dan Bali.

\section{Pembahasan}

\section{II.1. Pengertian Tantrayana.}

Tantrayana berarti kepercayaan yang berkaitan dengan Tantra, yaitu pelajaran atau doktrin yang berdasarkan pada masalah perbuatan gaib dan bersifat mistik. Zoetmulder mengatakan bahwa Tantra berarti: model, doktrin, aturan, karya ilmiah dan karya tertentu yang berisi pelajaran tentang perbuatan gaib dan mistik (Zoetmulder, 1982; 1933). Kelompok atau pengikut aliran Tantra disebut Tantragata. Sedangkan kata Tantrayana, apabila diuraikan terdiri atas kata tantra dan ayana, dalam Bahasa Sanskerta ayana berarti kendaraan, jadi yang dimaksud di sini adalah aliran atau kepercayaan tentang Tantra. Sedang kata Tantra sendiri berasal dari kata tan (berkembang, meluas) dan tra menunjukkan tempat. Menurut Gosta Liebert, kata Tantra berarti: doktrin, aturan dan suatu karya yang berkaitan dengan masalah mistik dan magi. Dalam perkembangan selanjutnyaTantra berarti: penghormatan kepada para dewi.(Liebert, 1976).

Tantrayana disebut juga dengan istilah Vajrayana, yang merupakan bentuk Tantra dalam agama Budha-Mahayana yang mempunyai sifat keraksasaan atau demonis.(Suleiman, 1954). Menurut arti katanya Vajrayana terdiri atas kata Vajra 
berarti: petir, senjata atau juga merupakan lambang kekuatan dari Sang Budha. Dalam aliran Siwa-Tantra, Vajrayana dihubungkan dengan bentuk lingga sebagai manifestasi Siwa.(Liebert, 1976). Inti ajaran Tantrayana adalah persatuan antara jiwa manusia dengan Yang Maha Esa, jalan untuk mencapai tujuan itu ialah dengan melakukan Yoga. Yoga di dalam ajaran Tantrayana menurut pengertiannya dapat dibedakan menjadi dua ajaran pokok yaitu: aliran kiri (nivrtti) dan aliran kanan (pravrtti). Aliran nivrtti, yang diutamakan adalah melakukan Panca-ma sepuas-puasnya. Panca-ma sendiri terdiri atas : matsya/ikan, mamsa/daging, mudra, madha/minuman keras dan maithuna/hubungan sex. Sebaliknya, pravrtti berusaha menentang dan menghilangkan panca-ma tersebut (Soediman, 1977).

Di Indonesia, aliran Tantrayana tidak lepas dari pengaruh kepercayaan asli, sedangkan unsur kepercayaan asli yang mempengaruhi adalah dinamisme atau kepercayaan terhadap kekuatan gaib, terutama yang berkaitan dengan perbuatan gaib atau magi, baik magi hitam maupun magi putih. Khusus di Bali, masalah ilmu hitam yang disebut pangiwa yaitu suatu ajaran tentang guna-guna, sampai sekarang masih ada. Hal ini dapat diketahui dari sumber tertulis/lontar-lontar. Begitu pula dengan ajaran pangiwa dan panengen yang pada hakekatnya saling bertentangan seperti halnya ajaran nivrtti dan pravrtti di atas (Haryati, 1985). Meskipun kedua ajaran itu mempunyai tujuan yang sama yaitu mencapai moksa atau kelepasan terakhir menuju sorga.(Parisada Hindu Dharma, 1978).

\section{II.2. Upacara Ritual Penganut Tantrayana}

Bagi penganut Tantrayana, ada beberapa hal penting yang biasa dilakukan dalam menjalankan upacara pemujaan, untuk mencapai tujuan akhir atau moksa. Tujuan ini dapat dilaksanakan dengan jalan melakukan Yoga, samadhi, mengucapkan mantramantra tertentu bahkan sampai menggunakan suatu alat bantuan yang disebut Yantra. Di Indonesia berdasarkan sumber yang ditemukan, dikenal beberapa upacara yang berhubungan dengan aliran Tantra tersebut. Sedangkan mengenai upacara ritual penganut Tantrayana ada beberapa cara yang dilakukan, antara lain :

\section{II.2.a. Yoga}

Yoga yaitu bermeditasi dengan jalan memusatkan pikiran dan mematikan panca indra. Menurut pengertiannya Yoga dibedakan menjadi empat, yaitu :

- Mula-Yoga (Yoga dasar) berarti membayangkan dewa atau bhatara di angkasa.

- Madhya-Yoga (Yoga menengah) berarti membayangkan bhatara di dalam badan. 
- Vasana-Yoga (Yoga akhir) berarti membayangkan bhatara dalam "mandala tanah" atau di bumi.

- Anta-Yoga (Yoga dalam) berarti membayangkan bhatara dalam "mandala ketiadaan" atau di alam gaib (Pott, 1966).

Dalam perkembangan selanjutnya Yoga dapat dibedakan menjadi beberapa pengertian yaitu :

- Kriya-Yoga : usaha pemisahan jiwa dari dunia nyata, dicapai dengan cara berpuasa, bertapa atau melakukan perbuatan baik lainnya.

- Jnana-Yoga : usaha mempersatukan jiwa dengan Yang Maha Tinggi, hal ini bersifat pribadi dan dapat dicapai dengan melakukan meditasi yang pada akhirnya akan mencapai tingkat pengetahuan (kesadaran tertinggi) dan pembebasan terakhir.

- Raja-Yoga : berarti yoga kerajaan.

- Hatha-Yoga : Yoga ini bersifat rahasia dan hanya diketahui oleh para pengikutnya (ibid).

Selain pengertian di atas, juga masih dikenal beberapa hubungan lainnya dari pengertian Yoga tersebut, antara lain :

- Mantra-Yoga yaitu Yoga yang ditekankan pada pengucapan berulang-ulang suatu mantra.

- Laya-Yoga yaitu Yoga yang ditekankan pada konsentrasi atau pemusatan jiwa. dan pikiran.

- Bhakti-Yoga yaitu Yoga yang ditekankan pada penyerahan diri atau kebaktian kepada Yang Maha Tinggi.

- Karma-Yoga yaitu Yoga yang ditekankan pada perbuatan baik atau karma manusia (ibid).

Menurut Patanjali, seorang filsuf Yoga yang diperkirakan hidup sekitar tahun 200SM$500 \mathrm{M}$, Yoga dibagi menjadi delapan tingkat yang disebut dengan istilah astangga Yoga. Lima tingkat pertama berkaitan dengan latihan tubuh disebut kaya-samskara dan tiga lainnya yang berkaitan dengan penyempurnaan jiwa disebut citta-samskara.

Secara singkat dapat dijelaskan bahwa kaya-samskara meliputi lima tingkatan yaitu :

- Yama, pengendalian atau pengekangan diri terhadap dunia luar, misalnya melakukan ahimsa (tidak membunuh semua mahkluk), tidak mencuri dan sebagainya).

- Niyama, perhatian penuh terhadap kesucian, kebersihan hidup, tapa-brata, mempelajari kitab suci dan penyerahan diri terhadap Tuhan.

- Asana, sikap duduk yang berkaitan dengan pencapaian moksa secepatcepatnya. 
- Pranayama, pengaturan nafas (menahan dan mengendalikan nafas) yang berkaitan dengan meditasi yang setepat-tepatnya.

- Pratyahara, menjauhkan diri dari benda atau obyek tertentu sehingga bebas dari ikatan samsara, misalnya dengan melakukan puasa dan ekagrata artinya melakukan konsentrasi terhadap benda tertentu, sehingga akhirnya mampu menguasainya dan lepas dari kesadaran.

Sedangkan citta-samskara meliputi :

- Dharana, kesabaran atau konsentrasi pikiran tanpa bantuan perasaan. Pikiran tidak boleh berpikir macam-macam tetapi berpusat pada hati, pusar atau ujung hidung.

- Dhyana, meditasi atau pemusatan pikiran sepenuhnya.

- Samadhi, pemusatan pikiran sepenuhnya yang lebih meningkat sehingga tidak merasakan lagi meditasi tersebut.(ibid).

\section{II.2.b. Sadhana}

Sadhana berarti pelaksanaan ajaran kejiwaan atau keagamaan, orang yang melakukannya disebut sadhaka (Noerhadi, 1982). Sadhana dilakukan bertujuan untuk memanggil dewa yang dipuja, dengan cara melaksanakan Yoga di bawah pimpinan seorang guru. Menurut aliran Tantra, guru Yoga mempunyai kedudukan penting bahkan dianggap merupakan penjelmaan dari dewa yang dipuja. Guru-guru tersebut dengan cara meditasi memperoleh ajaran-ajaran Tantrayana dari dewa, dan seterusnya harus diajarkan kepada para murid. Selanjutnya, murid-murid setelah mendapat pelajaran itu, harus melakukan sadhana, dengan tujuan menyatukan diri dengan dewa yang dipuja. Hal terpenting di dalam melakukan sadhana ini adalah cara meditasi sambil membayangkan dewa tersebut disertai pengucapan mantra-mantra atau katakata mistik (ibid). Sadhana dilakukan untuk semua jenis pemujaan, bail pemujaan yang bersifat nivrtti maupun pravrtti.(Liebert, 1976).

\section{II.2.c. Yantra}

Salah satu pemujaan Tantra dengan menggunakan Yantra. Seperti telah diketahui, bahwa yantra secara umum berarti alat Bantu untuk melakukan meditasi atau samadhi. Alat Bantu itu dapat berupa arca, gambar atau pahatan, diagram atau bentuk-bentuk tertentu misalnya bentuk lingkaran, segitiga octagonal dan sebagainya. Mengenai arti dan makna Yantra tersebut, Pott mengatakan sebagai berikut :

"The word Yantra, which means "aid" or "tool" is specially employed as the name of aids which are used by yogis as aids to medition and which can also in many cases be used as receptacles for the Istadevata" (Pott, 1966).

Di sini jelas bahwa Yantra selain digunakan oleh para yogin juga merupakan wadah bagi para Istadevata. Sedang yang dimaksud dengan Istadevata adalah: dewa yang 
dipilih perseorangan sebagai obyek pemujaan dan yang diharapkan dapat memberikan pertolongan atau bantuan (Liebert, 1976).

Sehubungan dengan masalah Yantra ini di dukuh Munggir, desa Pasrujambe, Kecamatan Senduro, Kabupaten Lumajang, telah ditemukan beberapa buah batu bertulis. Salah satu diantaranya bergambar sebuah diagram, oleh penduduk setempat disebut watu lintang karena gambar diagram itu memang menyerupai gambar bintang. Gambar diagram itu jelas melambangkan Yantra, yaitu alat bantu dalam melaksanakan samadhi.(Sukarto, 1986). Apabila di Pasrujambe terdapat lambang Yantra, maka menurut penelitian Pott, di Jawa Timur dan Jawa Tengah juga terdapat peninggalan arkeologi yang berupa lambang muladhara (Pott, 1966) yang juga berkaitan dengan aliran Tantrayana. Muladhara pada hakekatnya juga disebut mulapadma, perkataan mula berarti: akar, dhara (bhu) berarti: bumi dan padma adalah bunga teratai merah. Jadi secara keseluruhan berarti: bunga teratai yang berdaun kelopak empat lembar dan merupakan tempat tinggal ular naga betina yang bernama Kundalini. Dalam filsafat Tantrayana, di bagian ubun-ubun manusia terdapat kembang teratai yang berdaun kelopak seribu disebut sahasrarapadma, yang merupakan tempat tinggal dewa Siwa, sedangkan mulapadma tempat tinggal Dewi Kundalini terdapat di bagian anus. Untuk mencapai tingkat Yoga tertinggi, maka Dewi Kundalini harus digerakkan dengan samadhi supaya merayap ke atas melalui tulang belakang (Jawa: ulo-ulo) dan bersatu dengan dewa Siwa. Apabila telah terjadi persatuan antara dewa-dewi tersebut, maka seseorang yang melakukan Yoga itu telah mencapai tingkat tertinggi dan sempurna (ibid). Lambang muladhara itu dapat dilihat pula pada monumen dari Trawas, yang semula merupakan pancuran induk candi Jalatunda di lereng barat Gunung Penanggungan. Monumen Trawas berupa sebuah gunungan menyerupai lingga, dengan saluran di tengahnya dan dikelilingi delapan gunung lainnya yang lebih kecil. Seekor ular naga melingkar di bagian bawah yang didukung bantalan teratai dan berdaun kelopak empat lembar. Sekarang monumen Trawas ini disimpan di Musium Trowulan. (ibid).

Lambang muladhara/mulapadma lainnya ditemukan dalam prasasti tembaga Kaduluran. Tembaga Kaduluran berangka tahun 807 Saka atau 885 Masehi, tanpa menyebut nama raja, melainkan nama kepala desa (ramanta) di Kaduluran. Meskipun demikian, dapat diperkirakan bahwa tembaga Kaduluran berasal dari jaman pemerintahan Rakai Kayuwangi atau Dyah Tagwas. Bagian penutup prasasti itu dipahat dengan gambar bunga teratai yang berdaun kelopak empat helai. Karena gambar itu sangat kecil, maka di bagian tengahnya tidak terdapat gambar naga (Dewi Kundalini), melainkan sebuah titik atau bindu. Bindu itu sendiri dianggap merupakan suatu Yantra yaitu titik pusat dunia (Damais, 1970). 


\section{Penutup}

Sekilas melihat uraian di atas, dapatlah diambil kesimpulan bahwa merupakan salah satu ciri khas kebudayaan di Indonesia, adalah timbulnya proses pembauran atau sinthese antara unsur-unsur tradisi se tempat dengan kebudayaan yang datang dari India. Begitu pula sebaliknya, aliran Tantrayana di Indonesia banyak mendapat pengaruh kebudayaan lokal atau kebudayaan setempat.

Kelangsungan aliran Tantrayana sampai sekarang secara samar dapat dijumpai dalam bidang kesenian dan adat istiadat. Sebagai contoh: dalam kesenian Bali, dikenal cerita Calon Arang, Rangdha dan Barong yang berhubungan dengan ilmu sihir, demikian pula dalam tari-tarian yang memabukkan (Jawa: Tayuban). Sedangkan dalam adat istiadat, dijumpai adanya upacara korban seperti misalnya tabuh rah, metajen dan mecaru (Sutedja, 1986). Selain itu upacara memuja arwah nenek moyang dan memohon kesuburan dengan menggunakan candu sebagai sesaji, juga dapat dianggap merupakan sisa-sisa unsure tradisi aliran Tantrayana.

Tentang upacara pancama, tidak mengalami perkembangan bahkan sudah lenyap. Kemungkinan disebabkan karena upacara tersebut melanggar kesopanan, kesusilaan dan bertentangan dengan kepribadian bangsa Indonesia yang mempunyai dasar negara Pancasila. 


\section{KEPUSTAKAAN}

Bernet Kempers, AJ, 1954. Sedjarah Kebudayaan Indonesia; Universitas Gajah Mada; Yogyakarta

Damais,Louis Charles, 1970. Repertoire Onomastique de L'epigraphie Javanaise Vol. IX Paris : Ecole Francaise D'extreme Orient

Gosta Liebert, 1976. "Iconographic Dictionary of the Indian Religion" dalam JE. Van Lohuizen De Leeuw ed.Studies in South Asian Culture, Leiden : EJ.Brill.

Hall,DGE. 1960. A History of South-East Asia, Maxmillan \& Co Ltd. London.

Haryati Subadio, 1985. Jnanasiddhanta, Penerbit jambatan; Jakarta.

Kats, J. 1910. Sang Hyang Kamahayanikan, 's Gravenhage: Martinus Nijhoff.

Noerhadi Magetsari, 1982. Pemujaan Tathagata di Jawa pada Abad Sembilan (disertasi), Universitas Indonesia; Jakarta.

Parisada Hindu Dharma, 1978. Upadeca, TT. Denpasar.

Poerbatjaraka,R.Ng., 1951. Riwayat Indonesia I; Penerbit Yayasan Pembangunan Jakarta.

Pott,PH., 1966. Yoga and Yantra, Translation Series 8, Martinus Nijhoff; Leiden.

Slamet Mulyana, 1979. Nagarakretagama dan Tafsir Sejarahnya, Penerbit Bhratara, Jakarta.

Soediman, 1977. "Latar Belakang Keagamaan Candi Plaosan" 50 Tahun lembaga Purbakala dan Peninggalan Nasional 1913-1963, P.T. Karya Nusantara; Jakarta.

Atmodjo, S. K. (1983). Mengapa Phallus Arca Siwa-Bhairawa Di Pura Kebo Edan Menghadap Ke Arah Kiri?. Berkala Arkeologi, 4(1), 48-54. https://doi.org/10.30883/jba.v4i1.303

-------, 1986. "The Phallic Symbol on the Stone Inscription of Samirana", Untuk Bapak Guru, PT Dwikarya Cipta; Jakarta. 
Sutedja, I Wayan, 1986. "Arca Memegang Ayam Dikaitkan Dengan Tradisi Tabuh Rah di Bali", PIA IV; Puspan; Jakarta.

Zoetmulder, PJ., 1982. Old Javanese-English Dictionary 3 jilid; 's Gravenhage: Martinus Nijhoff. 